\title{
SER UM PROFESSOR PESQUISADOR
}

\section{Edna Scola Klein}

\section{RESUMO}

O Projeto "ESCOLA SINGULAR: AÇÕES PLURAIS", realizado na nossa unidade escolar, tem trazido a discussão e a reflexão para as nossas reuniões, compreensão de atitudes dos adolescentes e nossas enquanto profissionais. Trabalhar em grupo e viver com as diversidades é um grande desafio e também uma grande aprendizagem. Esta diversidade ocorre entre os colegas de trabalho e na própria sala de aula. Refletir sobre nossas ações nos traz a figura do professor-pesquisador. Realizamos diversas atividades na escola que trouxeram a todos uma maior participação nos espaços escolares, contato com a arte, com a pesquisa, com a observação. Estes processos ocorreram entre os alunos e com a equipe docente também. Participo de reuniões semanais, com os professores de $5^{\mathrm{a}}$ a $8^{\mathrm{a}}$ séries para trocas de idéias, estudo e discussões de textos e temas. Ouvir e participar das discussões com os diversos profissionais do Projeto sobre as teorias de aprendizagem, diversidades de estratégias utilizadas nas aulas ou formas de aquisição de conhecimento foi muito importante para o nosso trabalho. Interdisciplinaridade é o tema do subgrupo que participo e inicialmente o interessante do trabalho em grupo é realmente o fortalecimento de cada pessoa e a percepção de uma atitude interdisciplinar. Debatemos os conceitos de Interdisciplinaridade e planejamos algumas ações de forma interdisciplinar para aplicá-las com os alunos.

\section{PALAVRAS-CHAVES}

Professor-pesquisador; Interdisciplinaridade; Reflexão

\section{BE A RESEARCHER-TEACHER}

\section{ABSTRACT}

The "Singular school: Plural actions" project, created at our school unity, has been brought the discussion and reflection to our reunions, comprehension of teenage and ourselves attitudes, while professionals. Work in group and to live with these difficulties it's a great challenge and a great learning. This diversity it happens among the co-workers and at the classroom itself. Reflect about our actions bring us the image of the researcher-teacher. We did many activities at the school that brought to all a bigger participation at the school-places, contact with the art, with research, with the observation. These process happened with the students and the teaching staff too. I participate at weekly reunions, with teacher from 5th to 8th grades to exchange ideas, study and discussions about the texts and themes. To listen and to participate on the discussions with the diverse professionals from the Project about the learning theories, diversity of strategic used at the classes or the ways of knowledge acquisition was very important to our work. Interdisciplinary is the theme of the subgroup that I integrate and, at first, the interest point of the work at group is the strengthens of each person and the perception of an interdisciplinary attitude. We debate the Interdisciplinary concepts and plan some actions in interdisciplinary way to apply it with the students.

\section{KEYWORDS}

Researcher-teacher; Interdisciplinary; Reflection.

O Projeto "ESCOLA SINGULAR: AÇÕES PLURAIS", realizado na nossa unidade escolar, tem trazido a discussão e a reflexão para as nossas reuniões, compreensão de atitudes dos adolescentes 


\section{DIMENSÕES RELACIONAIS NA ESCOLA Grupo de Pesquisa em Ensino Superior}

e nossas enquanto profissionais. Tenho vivido em minha vida profissional a grata satisfação de trabalhar em grupo e aprender com cada um dos que aí participam, mesmo nas situações onde as idéias e conceitos não são uniformes. Viver com as diversidades é um grande desafio e também uma grande aprendizagem. Esta diversidade ocorre entre os colegas de trabalho e na própria sala de aula...

Perceber-me uma professora pesquisadora me anima muito para as minhas atividades diárias, para as minhas decisões, para as reflexões. Estou terminando este ano letivo sem aquele cansaço que é característico a todos os professores em Novembro... Desânimo e estresse não me dominaram por completo, apenas em algumas ocasiões. Realizamos diversas atividades na escola que trouxeram a todos uma maior participação nos espaços escolares, contato com a arte, com a pesquisa, com a observação. Estes processos ocorreram entre os alunos e com a equipe docente também. Assim, fica para mim este sentimento de satisfação em trabalhar em uma Unidade Escolar onde a preocupação é conversada e discutida, mesmo que não tenhamos a mesma opinião sobre tudo (o que seria humanamente impossível) "as cartas são colocadas na mesa". O fato de realizarmos Seminários entre todos os participantes do Projeto para a socialização das descobertas, angústias, idéias, e trabalhos realizados em cada subgrupo é muito interessante, pois nos ajuda a organizar os pensamentos, exercitar a nossa forma de registrar e também conhecer as atividades e pesquisas dos outros subgrupos.

Acredito também que sendo a Psicologia a nossa tônica e fundamento para o Projeto, isso nos traz questões relacionadas aos métodos de aprendizagem, desenvolvimento da criança e do adolescente e à compreensão do trabalho docente, temas discutidos e estudados no Grupo de Trabalho. Em nosso Projeto (2003) enviado para a FAPESP há a indicação de que:

Ao professor pode ser demonstrado que quando suas ações dão os resultados esperados, isto quase nunca ocorre em decorrência de iniciativas ocasionais, particulares e isoladas. É fundamental que a discussão sobre o cotidiano escolar ocorra de forma coletiva e sistemática, de modo que quando a Psicologia é chamada a auxiliar sobre o processo ensino-aprendizagem, ela não seja responsável por fornecer boas idéias, mas, sim, promover no grupo de professores uma união entre teoria e pratica nas ações cotidianas.

O professor pode ser auxiliado a se perceber como um profissional cujo conhecimento é influenciado por suas experiências (Larrosa, 1996,1999) e por suas reflexões a respeito delas, e também produzido pelo constante diálogo (no sentido posto por Bakhtin, 1986), entre essas duas instâncias. Na medida que o corpo docente é auxiliado a refletir sobre sua prática, a re-significar suas teorias, a compreender as bases de seu pensamento, tornando-se um pesquisador de sua ação, ele pode modificála com mais propriedade. Uma vez que, quando ele entra em classe, fica sozinho com suas crenças e teorias a respeito dos alunos, das estratégias de ensino e de avaliação, dos seus saberes e dificuldades, e 


\section{DIMENSÕES RELACIONAIS NA ESCOLA \\ Grupo de Pesquisa em Ensino Superior}

suas tomadas de decisão vão depender, fundamentalmente, dos pressupostos que ele tem para subsidiar a sua ação. (EMEF Padre Francisco Silva et al, 2003, pg. 6).

Nossas leituras e discussões de textos trazidos pela equipe universitária que nos assessora (Ana Aragão, Guilherme, Tamara e Paula), as dinâmicas apresentadas e vividas, as aulas expositivas e os debates sobre os temas estudados nos embasou e, às vezes, nos balançou quanto a conceitos já préestabelecidos. Este espaço das reuniões semanais para as trocas de idéias é riquíssimo dentro da escola. Ouvir e participar das discussões com os diversos profissionais do Projeto sobre as teorias de aprendizagem, diversidades de estratégias utilizadas nas aulas ou formas de aquisição de conhecimento foi muito importante para o nosso trabalho. O que também ganhamos com a equipe universitária é o exercício de redigir nossos textos, tanto os relatos das atividades que realizamos semanalmente nos subgrupos, quanto os relatos das reuniões que são redigidos por cada participante e depois lido e corrigido, como o relatório semestral. Ao escrever também fazemos nossas reflexões, correções e estabelecemos os conceitos.

Participei do subgrupo "Interdisciplinaridade" com as professoras Maria (Português), Carmem (História), Conceição (Português) e Giselda (Professora substituta contínua do período vespertino). Realizamos nossas reuniões preferencialmente nas quintas feiras à noite, quando discutimos estratégias, estudamos e debatemos textos, planejamos atividades e aulas para os alunos de $6^{\mathrm{a}}$, $7^{\mathrm{a}}$ e $8^{\mathrm{a}}$ séries.

O Interessante do trabalho em grupo é realmente o fortalecimento de cada pessoa. Assim, para mim, estes nossos encontros (iniciados em 01 de Outubro/2004) ajudou a nos conhecermos melhor, formarmos nossos conceitos quanto à Interdisciplinaridade que traz várias interpretações. Buscamos nossos relatórios do Projeto Flora Fanerogâmica do Estado de São Paulo (também financiado pela Fapesp $^{1}$ - 1998-2000) de onde retiramos alguns conceitos de interdisciplinaridade já estudados pelo grupo naquela época, (no caso eu e a professora Maria, de Português), e discutimos com o grupo atual. Fizemos leitura de alguns outros autores e dentre eles um foi alvo de novas considerações a respeito de Interdisciplinaridade:

A interdisciplinaridade pode ser percebida como esse conhecimento produzido quando as fronteiras deixam de ser linhas estanques, rígidas, que aprisionam e se flexibilizam, assumindo múltiplas possibilidades (Furlanetto, 2000 pg.88-89).

Pensar que as fronteiras entre as disciplinas assumem o papel de transgressão no sentido de inovar, possibilitar encontros, trocas e diálogos nos trouxe um novo olhar para as nossas dificuldades

${ }^{1}$ Processo n $^{\circ} .97 / 02322-0$

(C) ETD - Educação Temática Digital, Campinas SP, v.7 , n. esp , p.28-32 jun. 2006 - ISSN: 1676-2592. 30 


\title{
DIMENSÕES RELACIONAIS NA ESCOLA Grupo de Pesquisa em Ensino Superior
}

em sair das nossas disciplinas específicas. As fronteiras delimitam e mostram o outro lado... Muito bom este olhar...

\begin{abstract}
Pode-se compreender, então, que trabalhar a interdisciplinaridade não significa negar as especialidades e objetividade de cada ciência. O seu sentido reside na oposição da concepção de que o conhecimento se processa em campos fechados em si mesmos, como se as teorias pudessem ser construídas em mundos particulares sem uma posição unificadora que sirva de base para todas as ciências e isoladas dos processos e contextos histórico-culturais (Siqueira e Pereira, 1995). A interdisciplinaridade tem que respeitar o território de cada campo do conhecimento, bem como distinguir os pontos que os unem e que os diferenciam. Essa é a condição necessária para detectar as áreas onde se possam estabelecer as conexões possíveis. Como observa Gusdorf (1976:26 apud Siqueira e Pereira, 1995), "a exigência interdisciplinar impõe a cada especialista que transcenda sua própria especialidade, tomando consciência de seus próprios limites para colher as contribuições das outras disciplinas" (EMEF Padre Francisco Silva et al, 2003, pg 19).
\end{abstract}

O trabalho com os alunos de forma interdisciplinar foi planejado para acontecer no último trimestre do ano letivo, em decorrência dos subgrupos terem se formados no segundo semestre. Pensamos que este trimestre seria como um “piloto” para exercitarmos o planejamento e elaboração do trabalho com esta equipe. Os temas escolhidos foram: trabalho, escravidão e discriminações em geral, pois estes assuntos já estavam em andamento com os alunos de $6^{\mathrm{as}}, 7^{\mathrm{as}}$ e $8^{\mathrm{a}}$ séries, pelas três professoras de Português, e uma de História e traziam uma certa ligação. Tive dificuldades em encaixar os temas em todas as séries, pois já estava trabalhando com os conteúdos específicos. Consegui, no entanto, fazer uma ligação com o estudo de Sangue e Circulação Sanguínea com as sétimas séries e o problema de anemia falciforme que está presente na raça negra. Conseguimos folhetos da Secretaria de Saúde que explicam o problema e alertam a população para o tratamento; livros didáticos na biblioteca da escola e textos na Internet. Os alunos estavam em fase de elaboração de trabalho na forma de seminário, e dois grupos estudaram e apresentaram em sala de aula o tema. Foi bom o resultado. Temos como propostas para 2005 fazer o planejamento das atividades no início do ano letivo (e em cada início do trimestre) de forma que cada programa específico de cada disciplina tenha intercâmbios e ligações nos temas estudados. Corroborando este nosso pensamento, temos:

O ponto de partida e de chegada de uma prática interdisciplinar está na ação pedagógica. Desta forma, através do diálogo que se estabelece entre as disciplinas, evidencia-se uma mudança de postura na prática docente. A interdisciplinaridade não se propõe a desconfigurar a identidade das disciplinas; pelo contrário, a idéia é que, estabelecido o diálogo, cada disciplina sirva de referência para as demais, intensificando o sentido e a identidade de cada uma delas. Assim, não se trata de propor a eliminação de disciplinas, mas, sim, da criação de movimentos que propiciem o estabelecimento de relações entre as mesmas, tendo como ponto de convergência a ação que se desenvolve num trabalho cooperativo e reflexivo. Alunos e professores, como sujeitos de sua própria ação, se engajam em um processo de investigação, re-descoberta e

(C) ETD - Educação Temática Digital, Campinas SP, v.7 , n. esp , p.28-32 jun. 2006 - ISSN: 1676-2592. 


\section{DIMENSÕES RELACIONAIS NA ESCOLA Grupo de Pesquisa em Ensino Superior}

construção coletiva de conhecimento. Ao compartilhar idéias, ações e reflexões, cada participante é ao mesmo tempo ator e autor do processo. Com isso, busca-se conseguir uma visão mais ampla e complexa da realidade, que tantas vezes aparece fragmentada pelos meios de que se dispõem para conhecê-la e não porque o seja em si mesma (Olguin, 2003, apud EMEF Padre Francisco Silva et al, 2003. pg 19).

Ao terminar este relato posso perceber que neste ano de 2004 nós, profissionais do Projeto, estudamos e trabalhamos de forma mais integrada, cooperativa e buscamos respostas para as questões com os alunos (disciplina, aprendizagem, conhecimento, motivação). Vem uma sensação de poder resolver as questões que se apresentam em equipe e não solitariamente. Ao relembrar o ano de 2003, em que a Ana Aragão iniciou uma série de conversas e debates sobre o que queríamos na escola e como agir, me vem a sensação que estamos diferentes. Naquela ocasião havia um sentimento de desânimo e frustração em relação ao trabalho docente. Hoje me parece que estamos mais animados, mais valorizados, mais confiantes e com o sentimento de pertencimento a um grupo que tem como ideal a melhoria do ensino. E que pode resolver os problemas que forem surgindo.

\section{REFERÊNCIAS}

FURLANETTO, E. C. “O Papel do Coordenador Pedagógico na Formação Continuada do Professor: Dimensões Interdisciplinares e Simbólicas”. In: Interdisciplinaridade: formação de profissionais da educação. QUELUZ, Ana Gracinda (organizadora) São Paulo: Pioneira, 2000.

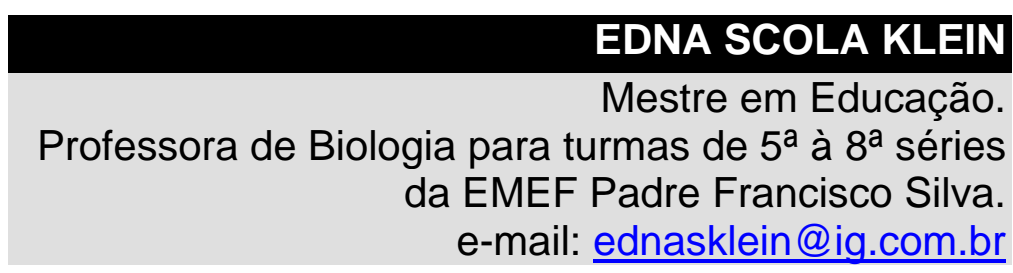

ARTIGO RECEBIDO EM: 10/01/2006-05

Aceito para publicação em: 09/05/2006

(C) ETD - Educação Temática Digital, Campinas SP, v.7 , n. esp , p.28-32 jun. 2006 - ISSN: 1676-2592. 